\title{
LA CUESTIÓN DE LAS SOCIEDADES POSAPOCALÍPTICAS Y EL MIEDO AL FIN DEL MUNDO: EL CASO DE THE WALKING DEAD
}

\section{Por: Johan Espinoza-Rojas ${ }^{1}$ y José E. Méndez-Esquivel ${ }^{2}$, Universidad de Costa Rica y Universidad Nacional}

Recibido: 5 de mayo, 2015

Aprobado: 15 de noviembre, 2015 .

\section{Resumen:}

El artículo analiza las principales características de las sociedades posapocalípticas que emanan de los discursos provenientes del miedo fundamental del ser humano, es decir, la idea de su muerte y la búsqueda por conocer qué vendrá después. Para tal efecto, se analiza brevemente la serie televisiva The Walking Dead, la cual ofrece un posible escenario que refleja la dicotomía entre el miedo y la esperanza, provocados por la destrucción de la civilización.

\section{Palabras clave:}

Miedo, estudio de medios, The Walking Dead, sociedades posapocalípticas, historias posapocalípticas, fin del mundo.

\section{THE ISSSUE OF POST-APOCALYPTIC SOCIETIES AND THE FEAR TO THE END OF THE WORLD: THE CASE OF THE WALKING DEAD}

\begin{abstract}
:
This paper analyzes the main characteristics of post-apocalyptic societies which stem from the discourse coming from the fundamental human fear, this is, the idea of their own death and the search for knowing what comes next. To such purpose, the television series The Walking Dead is briefly analyzed, which presents a possible scenario that reflects the dichotomy between fear and hope provoked by the destruction of civilization.

\footnotetext{
1 Johan Espinoza Rojas es estudiante de Ciencias de la Comunicación Colectiva, en la Universidad de Costa Rica y estudiante de Sociología de la Universidad Nacional. Contacto: johanespinozarojas@gmail.com.

2 José Emmanuel Méndez es estudiante de Psicología de la Universidad Nacional, Costa Rica. Contacto: josuechino104@gmail.com.
} 


\section{Key words:}

Fear, media study, The Walking Dead, post-apocalyptic societies, post-apocalyptic stories, end of the world.

\section{INTRODUCCIÓN}

A lo largo de la historia, el ser humano se ha mantenido en constante evolución. Durante este tiempo, se ha tenido que unir a sus semejantes para prosperar en sus civilizaciones, sin embargo, han existido momentos en los que entra en un periodo de letargo: las grandes guerras y el caos causado por los sistemas totalitarios entre otros, son algunos de los ejemplos más conocidos de desunión y poco adelanto.

Para nadie es un secreto que estas situaciones muchas veces han venido a ser un talante de la configuración del miedo que siente la humanidad y la mayoría del tiempo, convergen en la cuestión metafísica de la muerte. De acá que podamos hacer eco de las palabras de Delumeau (2003) quien afirma que "el miedo es fundamentalmente el miedo a la muerte. Todos los temores contienen cierto grado de esa aprehensión, por esa razón el miedo no desaparecerá de la condición humana a lo largo de nuestra peregrinación terrestre" (p.11).

A todo esto hay que agregar que vivimos en un planeta interconectado por medio de las tecnologías de comunicación, las cuales pueden hacer más evidente el temor de las personas y diseminarlo a partir de sus discursos mediáticos, gracias a la reproducción de ideas asociadas para su beneficio económico. Dichos discursos se han hecho manifiestos, especialmente, a partir de la pantalla de la televisión, el cine y ahora, los medios digitales.

Uno de los discursos de mayor trascendencia en la actualidad es aquel que trata sobre el exterminio de la civilización como actualmente la conocemos; ocurre, entre otras razones, por las reflexiones de la humanidad sobre su impacto ambiental en el planeta y hasta por la idea de que hay un momento reservado por un ser divino para acabar con la especie humana, debido a su comportamiento y rebeldía para con su figura de poder.

De hecho, muchas de las historias que ocurren en escenarios posapocalípticos fundamentan el momento que viven por la intervención o más bien, la no-intervención, de un sujeto divino que ha dejado a la humanidad en la deriva.

La historia del final del ser humano más conocida en el mundo occidental es la que se narra en el libro bíblico del Apocalipsis, aquel que cuenta cómo la Tierra vive una serie de hecatombes antes de la venida de Jesucristo. Historias en la que monstruos y demonios, hasta criaturas malignas que se esconden en pieles humanas son parte importante de estos relatos.

Este mismo libro narra lo siguiente: 
Y los reyes de la tierra, y los grandes, los ricos, los capitanes, los poderosos, y todo siervo y todo libre, se escondieron en las cuevas y entre las peñas de los montes; y decían a los montes y a las peñas: Caed sobre nosotros, y escondednos del rostro de aquel que está sentado sobre el trono, y de la ira del Cordero; porque el gran día de su ira ha llegado; ¿y quién podrá sostenerse en pie? (Apocalipsis 5: 15-17, Biblia Reina Valera).

Precisamente las historias que nos muestran el final de la sociedad tal y como la conocíamos, proponen el desorden colectivo y el miedo entre aquellos que han logrado sobrevivir, así como la incesante búsqueda por la estabilidad de sus vidas nada dichosas. Sin embargo, no solo el miedo es parte transversal de dichas historias, como dualidad se ubica también la idea de la esperanza de que quizás exista una solución a estas peripecias. Por ejemplo, si seguimos citando el texto bíblico, el lector podría encontrar también un mensaje de esperanza que se vincula con la concepción de la segunda venida de Jesús como Salvador del mundo.

Estas ideas apocalípticas cristianas se vinculan con el llamado "milenarismo", el cual es entendido como

(...) la convicción de que habrá, entre el tiempo que vivimos, con sus desgracias y sus crímenes, y la eternidad posterior al último juicio, un periodo intermedio de paz y de felicidad en el mundo terrenal. Cristo reinará en este mundo con los "justos" resucitados. Este reino estará precedido por secuencias de cataclismos y de guerras, siendo más corta esta última secuencia que la primera (Delumeau, 2003 p.3). (El subrayado es nuestro).

Este tiempo que precede al reino del que habla Delumeau parece ser que se ha venido conceptualizando, sobre todo de manera estética, en la pantalla de los medios de comunicación: desgracias incesantes que viven los protagonistas, una experiencia casi eterna de la vida que se acaba en el filo del más allá, el terror a lo desconocido que nos atormenta mental y físicamente, monstruos nunca antes vistos, humanos salvajes dispuestos a enfrentar cualquier reto en pro de su bienestar, etc.

Dado este entorno, este artículo pretende contextualizar y puntualizar algunos de los contenidos más importantes y generales de la serie televisiva The Walking Dead, la cual se ha 
convertido en los años recientes en un referente de las producciones sobre pandemias globales y el género televisivo sobre zombis y todo lo relacionado con el fin de la civilización.

Valga hacer notar que acá no se detalla un corpus específico para el análisis, sino que se recurre a la generalidad de la serie, de manera descriptiva además, a partir de la vivencia de quienes escribimos como espectadores de ella. A lo largo del consumo de este producto televisivo, se han realizado apuntes que convertimos en puntillosas reflexiones que deseamos compartir a continuación.

\section{¿A QUÉ LE TENEMOS MIEDO?: EL MIEDO A NUESTRO FINAL}

Uno de los sentimientos primarios y fundamentales del ser humano es el miedo. André (2006) lo define como: "una señal de alarma cuya función es (...) avisarnos de un peligro para enfrentarnos mejor al mismo" (p.18). Esta emoción prepara a los individuos de cualquier amenaza que pueda atentar con su vida, y evitarles así daños y hasta la muerte.

Dentro del contexto que nos compete, donde se están estudiando relatos sobre el final de la civilización, perfectamente se pueden interpretar como una especie de advertencia, de lo que podría ser una de las formas de actuar de la raza humana ante estos complejos hechos.

Beck (2006) en su libro La sociedad del riesgo, propone el advenimiento de una nueva forma societal, llamada precisamente como el título que lleva dicho texto. Analizar este planteamiento resulta apropiado en este momento:

“(..) la sociedad industrial se despide del escenario de la historia mundial por la escalera trasera de los efectos secundarios, y no como se había previsto hasta ahora en los libros de imágenes de la teoría social con un estallido político (revolución, elecciones democráticas)" (Beck, 2006).

Para este autor, los seres humanos empiezan a vivir una nueva etapa, que transita hacia la cuestión de los riesgos causados por nuestra intervención en la naturaleza: crisis nucleares, contaminación y desestabilización del sistema social. Esta faceta se ve relacionada con el surgimiento de la modernidad reflexiva, espacio donde las clásicas instituciones sociales empiezan a perder su poderío y el individualismo toma un papel preponderante: “(...) los riesgos civilizatorios hoy se sustraen a la percepción y más bien residen en la esfera de las fórmulas químico-físicas" (Beck, 2006, p.32). 
No existe temor mayor que aquello a lo invisible. Nos causa terror lo que es imperceptible y todo aquello de lo que no podemos defendernos fácilmente. Nos saca de nuestro cómodo lugar que un ser invisible, como un virus, acabe con nuestra estabilidad política, social y económica. Y no es casual que, precisamente en los últimos años, la humanidad ha vivido una serie de situaciones relacionadas con las enfermedades que se han expandido a lo largo del planeta. Si se hace memoria, las más recientes pandemias ocurrieron en 2009, por la gripe $\mathrm{AH}_{1} \mathrm{~N}_{1}$ (en la cual murieron cerca de 18.000 personas) y la más reciente, la del ébola, que surgió en 2014 y fue mermada en 2015. Afectó a gran cantidad de países de África Occidental y fue catalogada por la Organización Mundial de la Salud (OMS) como una de las epidemias “(...) más importante, más grave y más compleja de los casi cuatro decenios que han transcurrido desde que se reconoció la enfermedad" (s.f., párr.1).

Ante estas dos situaciones hubo cientos de relatos en los medios de comunicación que incitaban al miedo colectivo, por la posibilidad de que gran parte de las personas en el mundo en^fermaran y murieran.

Relacionado con esto, Camacho Markina (2009), parafraseando a Rincón y Rey (2008), asegura que:

(...) si somos la sociedad del miedo no es por los peligros objetivos que nos acechan, sino "porque los medios de comunicación están contando ese cuento", ya que ellos hacen negocio explotando las historias de miedo, que son las que generan audiencia, al mismo tiempo que nos hacen vivir en una situación de angustia permanente (p.3).

Y es que existe gran cantidad de historias que suscitan al miedo, pero aquellas relacionadas con las pandemias o enfermedades son más susceptibles de ser transmitidas por los medios de comunicación, debido a su carácter escénico, el cual logra representar de manera fácil lo que se vive a partir de las imágenes sangrientas, de sufrimiento y dolor que viven las personas enfermas. A lo anterior se debe agregar el hecho de que hay una cuestión que provoca angustia, porque existe el miedo a salir a la calle y toparse con alguien que fácilmente, puede contagiarlo a uno.

En relación con esto, Reguillo (2000) explica:

(...) a los miedos "invisibles", a la crisis sistémica, a la desconfianza en las instituciones, a la percepción difusa de las fuentes de amenaza, la sociedad responde 
con la construcción de figuras, relatos y personajes que son transformados en los verdugos de la sociedad (párr.42).

En el caso que se está analizando aquí, este lugar es tomado por la figura de los zombis. Valga aclarar que el término "zombi”, como lo consideran Ferrero y Roas (2011), se refiere a un "este monstruo que se basa en la idea del fantasma, porque en algún sentido no está ni vivo ni muerto. Vive en medio de nosotros, pero no es uno de nosotros”. Estos autores afirman también que el zombi es figura que representan algunas de las características de muchos individuos actuales: el adormecimiento mental, la alienación y la individualidad: "El zombi representa así a ese ser humano que ha perdido su humanidad, y es esa pérdida de humanidad, transmitida por nuestros semejantes como un virus, la que nos aterroriza realmente" (p.204).

La serie televisiva en cuestión muestra también al zombi como una figura que recoge el pensamiento cristiano de la muerte como purificación, donde el mundo posapocalíptico se ha vuelto de alguna forma un purgatorio, es decir, una escalera de entrada para vivir la eternidad prometida.

En este punto del análisis, vale la pena preguntarse por qué resulta posible que este tipo de series televisivas, las cuales contienen discursos sobre el miedo posapocalíptico, mantengan un lugar privilegiado en el imaginario social. Al respecto, Aguado Peláez (2014) apunta: "estas producciones, pese a ser ficciones, hunden sus raíces en la realidad y dejan ver parcelas de la misma ayudándonos a comprender, imaginar y también construir todo un entramado simbólico sobre el mundo que nos rodea" (p. 281). Es decir, hay un claro entrecruzamiento entre la realidad y lo ficticio, un fenómeno que pese a no ser nuevo en los medios de comunicación, se presenta con más fuerza en series como esta, debido a su capacidad narrativa y visual que atrapa a los espectadores.

Siguiendo esta línea, se encuentra Del Molino García (2013), quien analiza los productos cinematográficos surgidos durante la Guerra Fría y explica cómo el cine tomó los hechos suscitados en torno a la cuestión nuclear para convertirlos en una idea fundante de sus historias. Desde su perspectiva, los medios de comunicación -como aparato políticoutilizaron -y siguen utilizando- estos discursos para el control político que beneficia las visiones de Occidente, y señala que es posible que estemos viviendo el surgimiento y consolidación de nuevos íconos de representación del miedo generalizado, algo con lo que se concuerda acá. El zombi, como hemos dicho, actualmente ha tomado este lugar: se ha 
transformado en el reflejo de las realidades que vive el mundo (hambre, desastres naturales, inseguridad, totalitarismo, terrorismo, violencia, guerra, entre otros).

Antes de tratar algunas particularidades de los zombis en la serie The Walking Dead, se analizarán las principales características de la concepción de las sociedades posapocalípticas.

\section{LAS SOCIEDADES POSAPOCALÍPTICAS}

Para referirse a este punto, es necesario antes definir el término "sociedad". Se emplea, entonces, la utilizada por De los Campos (2007):

Un agregado más o menos caótico de seres humanos, convencidos que forman parte de una agrupación natural de personas, una unidad distinta de cada cual de sus miembros, para cumplir, mediante la mutua cooperación, todos o algunos fines de la vida. Se diferencia de comunidad ya que en esta última, los integrantes, además de compartir aquella creencia, consideran que es buena (p. 33).

Basado en lo anterior, puede dilucidarse que las sociedades posapocalípticas en realidad son comunidades. De los Campos nos hace notar que, en The Walking Dead, las personas no viven en grupos mayores a 50 individuos, los cuales comparten la idea de sobrevivencia y de rehacer sus vidas, sin importar si se emplean medios anárquicos, inaceptables en la anterior civilización (como el homicidio y el saqueo, entre otros).

Sin embargo, su fin último es restablecer la sociedad en la que vivían antiguamente, y por lo tanto, la visión de comunidad se convierte entonces en un medio para hacerlo. Esos grupos resultan empujados a esta forma de relación humana, que establece como un domo que resguarda sus intereses y sobre todo, su vida.

Para dejar clara esta diferencia entre sociedad y comunidad, Tönnies (2002) aclara que la comunidad es la forma de socialización en la que los individuos logran tal acercamiento, que se da un consenso basado en la solidaridad, la cual busca el beneficio de todos sus miembros. Por su parte, la sociedad se basa en leyes que regulan de alguna u otra forma las relaciones entre los sujetos, y se busca el mayor beneficio individual.

Fuera de estas pequeñas comunidades que nos muestran las historias posapocalípticas, vive y se desarrolla la degradación máxima de lo que alguna vez fue la sociedad (antes del cataclismo que la llevó al caos). Nuevamente aquí se refuerza la idea de que la comunidad como tal, es solamente un punto de tránsito por el que debe pasar la humanidad para alcanzar 
la sociedad que esperan germinar. De más está apuntar la semejanza con la Nueva Tierra y el Nuevo Cielo que promete la segunda venida de Jesucristo, y de la cual se hizo mención al inicio de este documento. Así, la cuestión de la esperanza vuelve a ser un tema fundamental para entender este fenómeno de lo posapocalíptico.

Este término de lo posapocalíptico hace referencia además a lo que pasa en el lugar específico de los acontecimientos posteriores al evento o crisis principal, cuyas consecuencias han generado un cambio de vida drástico en las personas, y ocasionado una enorme pérdida, tanto material como humana. Al analizar varias novelas, series televisivas, etc. del género relacionado con las catástrofes globales, esto queda demostrado. Empero, aún hay mucho que discutir sobre cómo definir la forma de vida presentada por los discursos posapocalípticos. Acá se prefiere continuar llamándolas sociedades posapocalípticas.

Por otra parte, Fatás (2001) señala que el atractivo en estos discursos se debe a:

(...) su condición excepcional, milagrosa y resolutiva: todo será, cuando el momento llegue, definitivamente sopesado, sentenciado, esclarecido; cesará toda muerte, terminará todo mal (excepto para quienes lo hayan merecido a juicio de quien no puede errar). Temor de muchos y esperanza de otros, situación paroxística y anómala, estertor final del valle de lágrimas que se resuelve en cielo y en infierno permanentes (...) (p.20).

Es así entonces que la idea de estas sociedades refleja el constante juego emocional, por llamarlo de alguna forma, por el que pasan los seres humanos entre la esperanza y el miedo a lo que vendrá; su preocupación escatológica lleva a crear posibles escenarios en los que la especie pueda moverse: "Nuestra imaginación continuamente trabaja hacia la peor posible interpretación de los eventos. Las expectativas de alguna catástrofe de gran alcance son regularmente ensayadas en relación a la variedad de riesgos" (Furedi, 2006, p.29).

Por último, en la reseña del libro El miedo. Historia de una idea política de Corey Robin, Pincheira Torres (2010) explica que este autor argumenta que el miedo es también una herramienta política más que un agente, que busca salvarnos al activar mecanismos para preservar nuestra vida.

De hecho si se reflexiona sobre las historias de las sociedades posapocalípticas, puede notarse que se caracterizan por mostrar que muchas veces el miedo de las personas se termina convirtiendo en una herramienta de control para quienes ostentan el poder en estos sistemas societales. 
Surge de lo anterior la pregunta de quiénes ostentan el poder durante el caos. Desde nuestro punto de vista y tomando como partida estos discursos -sobre todo desde The Walking Dead-puede afirmarse que lo tienen quienes conocen el uso de distintas armas para la protección, así como de supervivencia, autoridad rígida y, sobre todo, de estrategia.

En estas sociedades, el poder está establecido por la cuestión militar, y es es tomado por lo técnico y estratégico, que al fin y al cabo, como se ha dicho antes, busca mantener la vida a costa de cualquier acción.

Seguidamente se analiza una de las series contemporáneas con mayor audiencia, The Walking Dead, desde lo planteado en las páginas anteriores.

\section{THE WALKING DEAD COMO REFLEJO DE LA SOCIEDAD POSAPOCALÍPTICA}

The Walking Dead surgió primeramente en la novela gráfica desarrollada por el estadounidense Robert Kirkman en 2003. Posteriormente en 2010 la productora televisiva AMC estrena la serie en la pantalla chica.

No es extraño que la serie se haya estrenado un año después de los acontecimientos suscitados por la gripe AH1N1, además de “(...) en medio de una crisis financiera, revueltas sociales en Europa (...) y sobre todo en medio de cambios que afectan a cada rincón del mundo" (Cervantes Pérez, 2014, p.113).

Esta serie muestra un mundo posapocalíptico, donde un grave y mortal virus arremete contra todos los seres humanos, a quienes convierte en caníbales salvajes y extremadamente peligrosos. Los sobrevivientes del virus se ven obligados a vagar por las ciudades y campos en búsqueda de un refugio, seguro de todo peligro (zombis y seres humanos), con acceso a alimentos y a agua potable.

En la serie, los sistemas de organización tradicionales, como los gobiernos y demás instituciones, han sido relegados por el caos. Por tanto, se crean pequeños grupos o pandillas que protegen a los suyos y sus recursos. La humanidad ha regresado obligadamente a su periodo de nómadas.

Durante las tres temporadas iniciales, la serie exhibió la lucha del grupo de Rick Grimes - personaje principal-, un antiguo alguacil dispuesto a todo por proteger a su familia y amigos, por sobrevivir y por encontrar un lugar donde resguardarse de la catástrofe.

En estos primeros capítulos se exponen las principales consecuencias del virus: incontable cantidad de muertes, desorden social, político y económico, incomprensibilidad por los acontecimientos y peleas entre pequeños grupos sociales, cada vez más territoriales por su sobrevivencia. 
En la cuarta y quinta temporadas entran otras consideraciones a la serie: el grupo ha encontrado un lugar donde asentarse y trata de construir un nuevo sistema de apoyo basado en la colaboración mutua (¿comunismo?). Además, trata de sobrevivir mayoritariamente de los humanos y no de los zombis y tiene que luchar contra aquellos que quieren desmantelar su nuevo hogar.

Aunque a lo largo de la serie parece que la esperanza se opaca, siempre hay una dualidad entre el final de todo y lo que puede haber más allá. Si bien Dios queda casi destituido en la pantalla, solamente se le nombra para achacarle lo sucedido. Hay un elemento escatológico de lo que puede ocurrir después de todo lo malo.

En los primeros capítulos de la quinta temporada, estrenada en 2014, el grupo es capturado por los habitantes de "Terminus", una comunidad donde supuestamente se ofrecía un lugar seguro, sin embargo, resulta ser una trampa. Posteriormente el grupo de Rick logra vengarse de esta comunidad y deambula por los bosques, hasta que son contactados por Aaron, un reclutador de un pueblo que se ha organizado social y políticamente. En este lugar hay una clara división de labores, una figura política preponderante y una infraestructura (muros) que resguarda y da seguridad a los integrantes del grupo.

La serie demuestra la apoteosis de un mundo sumido en el caos por el inminente final de lo que conocíamos como sociedad, el cual ocurre lentamente y con el sufrimiento de los sobrevivientes.

También señala la existencia de un miedo colectivo a este final y a la incertidumbre de qué podrá ocurrir a la mañana siguiente. Es, sin duda alguna, la máxima expresión de la teatralidad del apocalipsis que muestran los medios de comunicación, con sus efectos especiales y palabras que buscan atemorizar más que calmar. Precisamente "su éxito puede residir en (...) la posibilidad de visualizarnos en un escenario en donde una enfermedad global se traiga abajo la estabilidad política, social y económica de todo el mundo" (Espinoza Rojas, 2015, p.28).

The Walking Dead ha tenido gran impacto en la televisión. Basta mencionar que el inicio de la segunda parte de la quinta temporada fue vista por casi 16 millones de personas en los Estados Unidos (La Prensa, 2015), y para el momento en que se escribe este texto, se desarrolla la sexta temporada y se estrenó su spin-off, la cual lleva por nombre "Fear The Walking Dead" y cuenta el inicio del virus.

Ahora, ¿cuál es el motivo de que series como The Walking Dead sean populares en algunos sectores de la sociedad? Una posible explicación puede estar ligada con las creencias que puedan tener las personas respecto a la muerte. La percepción cristiana occidental sobre 
este fenómeno tiene las siguientes posibilidades: si la conducta del sujeto es reflejo de lo predicado por Jesús, podrá ascender al Cielo prometido, donde el dolor y la miseria no existen; en caso contrario se le condenará al fuego eterno -el Infierno- y pagará por sus pecados. Una segunda opción se posiciona con el dogma cristiano católico, el cual predica la existencia de un espacio entre, por decirlo de alguna forma, el Cielo y el Infierno, llamado Purgatorio, en el cual un sujeto murió bajo pecados veniales (un tipo de pecado leve, como por ejemplo un insulto) y no es lo suficientemente "puro" para estar en la presencia de Dios, por lo tanto estará en dicho lugar espiritual hasta que alcance la purificación de su alma. Otra forma de pensamiento respecto a la muerte es la postura escéptica, la cual afirma que el ser humano al morir no trasciende, simplemente deja de existir, deja de ser.

Sea cual sea el resultado de morir, el ser humano siente una rara fascinación por su destino y por lo relacionado con el "más allá" (ya discutido en párrafos anteriores). Para entenderlo con más detalle, Bauman (citado en Imbert, 2014) aclara: “(...) el miedo primario a la muerte es, quizás, el prototipo o el arquetipo de todos los miedos, el temor último del que todos los demás toman prestado sus significados respectivos" (p. 77).

A lo largo de la historia, hay ejemplos de civilizaciones en la Tierra que han llegado a su final, y por ende, las escenas vistas en The Walking Dead pueden mostrar aquellas conductas que para los personajes les serían castigadas en "la vida anterior", por ejemplo, la escena en la que Rick asesina a Shane por sus constantes cuestionamientos, intentos de cortejar e intimar con Lori -su esposa- y humillarlo frente a Carl -su hijo-, con lo que demuestra así su rol de líder. El personaje de Gleen por su parte, tiene la confianza para intentar tener una relación amorosa con Maggie, una chica que, según él, no lograría salir antes de que "el mundo se fuera al carajo". Otro ejemplo es el de Carol, quien posterior a la muerte de su esposo Ed, decide atacar su cadáver con un pico y desquitarse por la violencia doméstica de la cual había sido víctima por años.

Con este tipo de casos también se nota una metáfora de la transformación que tienen los sobrevivientes en relación con los zombis, ya que para sobrevivir han dejado su cotidianidad atrás y han tomado una nueva ética que apruebe sus conductas: sobrevivir.

Ante esta modificación de las conductas de los personajes se plantea la pregunta: ¿han perdido la humanidad o más bien se demuestra aún más en la serie? Para Rappaport (2001) la humanidad es "una cualidad personal, un nombre colectivo y un proyecto histórico. En cierto modo sentido, el proyecto de realizar nuestro potencial para ser colectivamente" (p.12), y tal como se menciona en el texto, este concepto ha evolucionado junto al ser humano en sí. 
Siendo así, en el contexto de The Walking Dead los sobrevivientes han tenido que renunciar a las antiguas reglas de los regímenes donde residían, donde existían leyes consensuadas sobre el comportamiento de cada quien, para optar por una forma de humanidad, donde la ley es sustentar las necesidades básicas, no dejar que alguien ajeno al grupo las tome, eliminar cualquier amenaza (ya sea humano o zombi) y repetir el ciclo para no fallar a su grupo.

En cuanto al problema de la humanidad en los discursos posapocalípticos, aclara Imbert (2014) que “(...) lo humano ya no funciona como valor, ni valor en sí -del orden de lo ético-, ni valor ecológico de respeto y mantenimiento del entorno" (p.88).

Hay otro elemento relacionado con esta cuestión de lo humano, y es que las expresiones artísticas y culturales -parte importante de las manifestaciones de la vida humana en sociedad- o incluso el ocio o toda característica que se pueda vincular con lo "civilizado" quedan postergadas por tiempo indefinidos. La especie empieza su degradación, la cual se compara -en algún sentido- con el modelo de vida específico de los primeros pasos de la humanidad en la Tierra.

Si se analiza bien, esta serie, al igual que la mayoría de discursos posapocalípticos mira la Edad Media como reflejo de las historias que viven sus personajes, por ejemplo, cuando el mundo se acorta a sus acontecimientos, que no hace falta pensar cómo está la situación de los demás lugares porque posiblemente lo estén pasando igual de mal. Por otra parte, aunque muchas veces la figura de un dios es negada, existe una suerte de pensamiento de que lo que ocurre es creación de un castigo engendrado por lo divino (ya se trató un poco de esto en líneas previas).

También resurge la concepción de monstruos y demonios, que acechan al ser humano para convertirse en su desgracia ${ }^{i}$.

Por último, es importante analizar el comportamiento de Hershel -un granjero- pues expresa actitudes de resilienciaii. En sus primeras apariciones en la serie, él mostraba cierta incredulidad ante la idea de que los zombis no son humanos y los consideraba simples personas enfermas (entre ellos su esposa y varios de sus familiares). Empero, durante los últimos capítulos de la temporada dos, sus parientes son eliminados y Hershel recae en el alcoholismo, al verse obligado a afrontar la realidad de que ellos no volverían a ser los mismos de antes, pues han perdido todo rastro de humanidad. Ya para la temporada tres, se muestra en pleno el proceso de resiliencia, porque tuvo que dejar de lado sus creencias pasadas sobre "los muertos vivientes". En él se observa un gran peso moral a partir de dicha temporada, que aunque haya sido asesinado plantea en los sobrevivientes la pregunta: ¿se 
puede empezar de nuevo durante lo que parece ser el fin de la civilización? Hershel entonces, es la antítesis de la pérdida de lo humano de la que estuvimos hablando.

\section{A MANERA DE CONCLUSIÓN}

La idea sobre las sociedades posapocalípticas ha tomado un lugar especial en nuestro actual mundo, derivado especialmente por la globalización del miedo, permitida y hasta motivada por los medios de comunicación colectiva.

A partir de la serie analizada, se concluye que las sociedades posapocalípticas involucran conceptualizaciones de una reconfiguración casi total de la sociedad, tal y como la conocemos en este momento. Por ejemplo, los personajes deben modificar su ética para sobrevivir, crear una nueva forma de relacionarse y reemplazar los grandes núcleos sociales por pequeñas comunidades, lideradas a su vez por personajes con conocimientos basados en lo técnico y estratégico.

Además, se concluye que desde hace mucho, la muerte es un recurso narrativo en los medios de comunicación, capaz de generar miedo, incertidumbre y morbo. Ayuda también a construir en la audiencia el imaginario de lo que podría convertirse nuestra civilización, si entrara en un momento de caos colectivo, asociado a una razón catastrófica que diezme importantemente la especie humana.

El interés económico que mueve el miedo, ha llevado a los medios a dedicar gran cantidad de espacio a estos temas, desde simples noticias hasta series televisivas hasta películas de gran formato.

No puede dejar de notarse cuán notoria se hace en esta serie la influencia de las creencias cristianas sobre la purificación de la humanidad ante la Segunda Venida de Jesucristo, es decir, los cataclismos por lo que han de pasar los habitantes de la Tierra para vivir eternamente en el "nuevo mundo".

Por último, resulta importante mencionar que “(...) Slavoj Zizek ha señalado que nuestra actual condición social e ideológica hace que nos sea más fácil imaginar el fin del mundo que una sociedad igualitaria y sin capitalismo. De este sustrato se nutre todo el género post-apocalíptico" (Herrera, 2014, párr.6). 


\section{NOTAS}

\footnotetext{
${ }^{\text {i }}$ Existe un estudio de Claude Kappler (2004) que analiza estos elementos durante la Edad Media.

ii El concepto de "resiliencia" se entiende aquí como la habilidad para exitosamente afrontar el estrés y los eventos adversos que proceden de la interacción de diversos elementos en la vida" (Becoña, 2006).
}

\section{Referencias bibliográficas}

André, C. (2006). Psicología del Miedo. España: Editorial Kairos.

Aguado Peláez, D. (2014). Cuando el patriarcado sobrevive al apocalipsis: análisis de The Walking Dead (AMC, 2010- ). Feminismo (23), pp. 279-297.

Becoña, E. (2006). Resiliencia: definición, características y utilidad del concepto. Revista de Psicopatología y Psicología Clínica (11), 3, pp. 125-146. DOI: http://dx.doi.org/10.5944/rppc.vol.11.num.3.2006.4024

Beck, U. (2006). La sociedad del riesgo. Hacia una nueva modernidad. España: Paidós.

Camacho Markina, I. (2009). Pánico infundado. Tratamiento del brote de "gripe A" en la prensa española. Recuperado de http://www.revistalatinacs.org/09/Sociedad/actas/19idoia.pdf

Cervantes Pérez, M. (2014). Zombie media: el ataque zombi en TV. Revista DOXA (4), núm. 7, pp. 107-120.

Del Molino García, R. (2013). El discurso del miedo apocalíptico y sus representaciones cinematográficas durante la Guerra Fría. Revista Comunicación y Ciudadanía, (6), pp. 6-15.

De los Campos, H. (2007). Diccionario de Sociología. Recuperado de http://www.hacienda.go.cr/cifh/sidovih/uploads/Libro/Diccionario\%20de\%20sociolog $\% \mathrm{C} 3 \%$ ADa.pdf

Delumeau, J. (2002). Miedos de ayer y hoy. En Villa Martínez, M. (Ed.), El miedo, reflexiones sobre su dimensión social y cultural (pp. 9-21). Medellín: Corporación Región.

Delumeau, J. (2003). Historia del milenarismo en Occidente. Historia Crítica, (23), pp. 1-14.

Espinoza Rojas, J. (2015). La mediatización del miedo en la sociedad del riesgo: los productos audiovisuales sobre pandemias globales. Manuscrito no publicado.

Fatás, G. (2001). El Fin del Mundo. Apocalipsis y Milenio. Madrid: Marcial Pons, Ediciones de Historia. 
Ferrero, Á. y Roas, S. (2011). El “zombi” como metáfora (contra) cultural. Nómadas, Revista de Ciencias Sociales y Jurídica, (32), 4, pp. 97-220.

Furedi, F. (2006). Culture of fear revisited. London: A\&C Black.

Herrera, R. (2014). Marx y Vattimo viendo The Walking Dead. Primera parte. Recuperado de http://www.revistapaquidermo.com/archives/10937

Imbert, G. (2014). Imaginarios posapocalípticos en el cine actual: entre la vuelta al origen y el fin de la humanidad. Contratexto, (22), pp. 75-89.

$\begin{array}{lllll}\text { Iglesias.net. } & \text { (s.f.). } & \text { Apocalipsis. }\end{array}$ http://iglesia.net/biblia/libros/apocalipsis.html

Kappler, C. (2004). Monstruos, demonios y maravillas a fines de la Edad Media. Madrid: Ediciones Akal.

La Prensa. (2015). Regreso de "The Walking Dead" fue visto por 15,6 millones de televidentes. Recuperado de http://laprensa.peru.com/espectaculos/noticia-thewalking-dead-temporada-5-episodio-9-rating-amc-estados-unidos-39046 el 4 de marzo de 2015

Organización Mundial de la Salud. (s.f.). Una epidemia de expansión rápida llena de sorpresas trágicas. Recuperado de http://www.who.int/csr/disease/ebola/ebola-6months/surprises/es/

Pincheira Torres, I. (2010). El miedo. Historia de una idea Política. Polis, 9(25), pp. 577-581.

Rappaport, R. (2001). Ritual y religión en la formación de la humanidad. Madrid: Ediciones Aka.

Reguillo, R. (2000). Los laberintos del miedo. Un recorrido para fin de siglo. Revista de Estudios Sociales, (5). Recuperado de http://res.uniandes.edu.co/view.php/113/1.php?ad=\%23

Rincón, O. y Reyes, G. (2008). Los cuentos mediáticos del miedo. Urvio, Revista Latinoamericana de Seguridad Ciudadana, núm. 5, pp. 34-45.

Tönnies, F. (2002). Community and Society. New York: Dover Publications. 